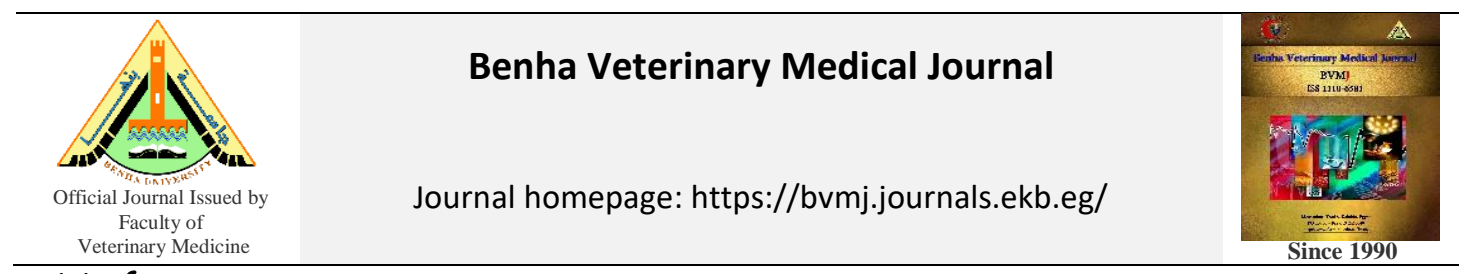

Original Paper

\title{
Protective effect of thymol and carvacrol on gentamycin-induced oxidative stress in maleAlbino rat
}

\author{
Ali, Sabry Mohammed ${ }^{1}$, Khalifa , Hesham Ahmed ${ }^{2}$, Yousef, Ahmed Samy, \\ ${ }^{1}$ Department of Pharmacology, Fac. Ve.t Med. , Cairo University \\ ${ }^{2}$ Department of Pharmacology, Fac. Ve.t Med. , Zagazig University
}

\begin{tabular}{|c|c|}
\hline ARTICLE INFO & ABSTRACT \\
\hline $\begin{array}{l}\text { Keywords } \\
\text { Antioxidant. } \\
\text { Carvacrol } \\
\text { Gentamicin } \\
\text { Thymol } \\
\text { Received } 10 / 10 / 2019 \\
\text { Accepted } 7 / 11 / 2019 \\
\text { Available On-Line } \\
\text { 12/05/2020 }\end{array}$ & $\begin{array}{l}\text { The current study aimed to investigate the protectiveeffect of the thymol }(20 \mathrm{mg} / \mathrm{kg} \text { BW) or } \\
\text { carvacrol ( } 15 \mathrm{mg} / \mathrm{kg} \mathrm{BW} \text { ) on gentamycin (100mg/kg) induced oxidative stress in rat. Thymol } \\
\text { and carvacrol were administrated orally once daily for } 12 \text { consecutive days. After one week of } \\
\text { acclimatization, } 30 \text { adult male albino rats weighting } 150-200 \mathrm{~g} \text { were used for the experiment. } \\
\text { They were allocated into } 5 \text { equal groups (n=6). group1 (control), group2 (tween), group3 } \\
\text { (gentamycin), group4 (thymol+gentamicin), and group5 (carvacrol+gentamcin). At the end of } \\
\text { experiment, Rats were euthanized humanly, and blood samples were collected to study the } \\
\text { nephro, hepatic and inflammation markers. The findings revealed that there were significant } \\
\text { decrease in serum blood urea nitrogen, creatinine and MDA in thymol and carvacrol groups } \\
\text { but there were significant elevation in renal SOD, CAT and GPXactivities. There were } \\
\text { significant decreases in ALT, ALP, AST and GCT in thymol and carvacrol groups. } \\
\text { Additionally, CRP, IL6and TNF- } \alpha \text { were decreased in thymol and carvacrolgps. The result } \\
\text { revealed that each of the thymol and carvacrol has antioxidant and protective effects against } \\
\text { the hepatic toxicity and nephrotoxicity induced by gentamicin in rats. }\end{array}$ \\
\hline
\end{tabular}

\section{INTRODUCTION}

Gentamicin, aminoglycoside bactericidal antibiotic, is effective against gram-negative bacterial infection (LopezNovoa et al., 2011).However, the therapeutic doses of gentamicin could induce hepatic toxicity and nephrotoxicity (Noorani and Gupta, 2010). Gentamicin-induced nephrotoxicity is functionally characterized by an increase in serum creatinine and blood urea nitrogenalbuminuria and urinary losses of creatinine, decrease in glomerular filtration rate, and renal dysfunction (Soliman et al., 2007). Gentamicin can also increase the generation of reactive oxygen species (ROS) like superoxide anions, hydroxyl radicals and hydrogen peroxides; Additionally,it can induce the reactive nitrogen species (RNS) in the renal cortex that eventually lead to renal structural and functional deterioration (Walker et al., 1999). Kidneys ofrat are more susceptible for ROS damage due to the induceddeficiency in antioxidant defense enzymes like superoxide dismutase and catalase(Pedraza-Chaverrí et al., 2000).

Oxidative stress is reported to play an important role in gentamycin toxicity (Dhanarajan et al., 2006). The oxidative stress is mediated by hydroxyl radicals from hydrogen peroxide $\left(\mathrm{H}_{2} \mathrm{O}_{2}\right)$ and superoxide anion which is called reactive oxygen species spices (ROS). The ROS directly act on the cell components, including lipids, proteins and DNA, and destroys their structure. Inflammation and tumor necrosis factor-alpha (TNF- $\alpha$ ) induced apoptosis also contribute in this toxicity (Basnakian et al.,2002).

Antioxidants are substances that prevent formation of ROSor other oxidants. These antioxidants could delay or inhibit the cellular damage mainly through their free radical scavenging property (Halliwell 1995). Herbal remedies are used worldwide to alleviate symptoms, treat illness and promote over all wellness. It was estimated that $60 \%$ of the world's population and $40 \%$ of Americans are use the herbal remedies (Astin ,1998).Among the most common natural bioactive compounds are plant secondary metabolites such as phenolic compounds. These include different kinds of substances,-either volatile or nonvolatile (Alinezhadet al., 2013).Among the volatile compounds, there are phenol derivatives of terpenes such as thymol and its isomer carvacrol(Nabavi et al., 2015).

Thymol (2-isopropyl-5-methylphenol) is the main monoterpene phenol found in the essential oils extracted from plants belonging to the Lamiaceae family, such as those of the genera Thymus, Ocimum, Origanum, Satureja, Thymbra, and Monarda(Tuttolomondoet al. , 2015). It has been demonstrated that thyme markedly inhibits the production of Tumor necrosis factor (TNF- $\alpha$ ) and Interleukin 6 (IL-6) in lipopolysaccharide-stimulated inflammatory response in mouse mammary epithelial cells (Lietal., 2014).

Carvacrol is a component of some medicinal plants, such as black cumin (Nigella sativa), oregano (Origanum-

\footnotetext{
* Corresponding author: Prof Ali, Sabry Mohammed. Department of Pharmacology , Fac. Ve.t Med. , Cairo University
} 
compactum), Monardadidyma, Origanumdictamnus, Origanummicrophyllum, Origanumonites, Savory (Saturejahortensis) (Aligianniset al., 2001).Some studies assured the efficiency of carvacrol in scavenging free radicals i.e. nitric oxide, superoxide radicals, peroxyl radicals and hydrogen peroxide (Kohen and Nyska ,2002 andAristatile et al., 2015).Carvacrol protects liver during renal ischemia/reperfusion injury and hepatic injury through improving liver antioxidant defense and minimizing the products of lipid peroxidation (Aristatileet al., 2009).

Thymol and carvacrol have been reported to cause inhibition of inflammatory edema and migration of leukocytes in an animal model. They also decrease the key mediators of inflammation, such as cyclooxygenase (COX)-2, and stimulation of the enzyme of nitric oxide synthase (iNOS) and inflammatory cytokines, such as $\mathrm{TNF} \alpha$, and C-reactive protein (CRP) (Gholijani et al., 2015).

Abdel-Raheemet al. (2009) investigated that injection of gentamicin $(100 \mathrm{mg} / \mathrm{kg} /$ day $)$ intraperitoneally for seven successive days in rats could induce biochemical and histopathological alterations in the rat's kidney. Clinically, the acute kidney injury manifests after 5-7 days of the therapy (Randjelovic et al. , 2017). Hence, it is used in our study for induction of nephrotoxicity in rats at the same dose. Acute kidney injury is diagnosed on the basis of BUN and serum creatinine levels. They are considered as the most reliable and feasible markers of renal function among other renal parameters (Malyszkoet al., 2015). Therefore, BUN and serum creatinine were estimated for evaluation of kidney functions in the current study. Moreover, this study was aimed to investigate the possible effect of thymol and carvacrol against the side effects induced by gentamycin via amelioration the oxidative stress, inflammation and apoptosis.

\section{MATERIAL AND METHODS}

\subsection{Drugs}

- Gentamicin $\left(\mathrm{C}_{21} \mathrm{H}_{43} \mathrm{~N}_{5} \mathrm{O}_{7}\right)$ : the product was bought from El Nasr Pharmaceutical Chemicals Co., Egypt. Each ampule contains gentamicin (as sulphate) $80 \mathrm{mg} / 2 \mathrm{ml}$.

- Thymol $\left(\mathrm{C}_{10} \mathrm{H}_{14} \mathrm{O},(100 \%\right.$ pure $)$ was used as a standard antioxidant, obtained from Alpha Company, India.

- Carvacrol $\left(\mathrm{C}_{10} \mathrm{H}_{14} \mathrm{O},(100 \%\right.$ pure $)$ was used as a standard antioxidant, obtained from Alpha Company, India

\subsection{Animals}

Thirty adult male albino rats of $150-200 \mathrm{~g}$ body weight were obtained from Faculty of Veterinary Medicine, Zagazig University. All animals were kept under observation for one week for acclimatization to the laboratory environment before starting the experiment. They were kept under hygienic condition in metal cages and were fed on barley and milk all over the experimental period and water was provided ad-libitum.

\subsection{Experimental design}

Rats were equally divided into 5 groups, 6 animals for each group, as follow:

Group $1(\mathrm{C})$ :Control group, rats in this group received normal saline orally
Group 2 (Tw): Tween group. Rats in this group received tween (the solution in-which the thymol and carvacrol were dissolved) orally.

Group $3(\mathrm{G})$ : Gentamycin treated group. Rats in this group intraperitoneal injected with $100 \mathrm{mg} / \mathrm{kg} \mathrm{B}$. wt. Gentamicin, once daily for 12 successive days.

Group 4 (TG): Thymol+Gentamicin treated group.Rats administrated $\mathrm{I} / \mathrm{P}$ with gentamicin $(100 \mathrm{mg} / \mathrm{kg} \mathrm{B}$. wt.)with thymolorally ( $20 \mathrm{mg} / \mathrm{kg} \mathrm{B}$. wt.) once daily for 12 successive days.

Group 5 (CG): carvacrol+Gentamicin treated group, the animals were I/P received gentamicin $(100 \mathrm{mg} / \mathrm{kg} \mathrm{B}$. wt.) and orally received carvacrol $(15 \mathrm{mg} / \mathrm{kg} \mathrm{B}$. wt.) once daily for 12 successive days.

Mortality and general condition of animals were observed daily throughout the whole experimental period.

\subsection{Tissue and Blood samples}

At the end of experiment, rats were euthanized humanlythrough decapitation and then blood, and tissue samples were collected.Two blood samples were taken from each animal. The first sample was collected in a centrifuge tube without anticoagulant and placed in a slant position then centrifuged at $3000 \mathrm{rpm}$ for 20 minutes to obtain the serum. The obtained serum was transferred to clean and dry Eppendorf tubes, and kept frozen at $-20^{\circ} \mathrm{C}$ for further biochemical analysis (liver and kidney function parameters). The second blood samples $(1 \mathrm{ml})$ was received in a clean tube containing disodium salt of EDTA and used for hematological examination. Tissue samples including liver and kidneys were immediately removed, half of them was kept in deep freezer $\left(-20^{\circ} \mathrm{C}\right)$ for measuring the tissue antioxidant enzymes. (SOD, GPx and determination of MDA concentration). The second half was kept in $10 \%$ neutral formalin for histopathological examination.

\subsection{Histopathological examination:}

Samples from the kidney and liver obtained from all groups were collected and fixed in $10 \%$ neutral formalin prior to routine processing in paraffin wax. Sections ( $5 \mu \mathrm{m}$ thickness) were cut and stained using Hematoxylin and Eosin (H\&E) and then examined microscopically according to Bancroft and Gamble(2008).

\subsection{Statistical analysis}

Collected data were statistically analyzed through F-test one way (ANOVA) using the software statistical program (SPSS, ver. 16.00, USA). Data were expressed as the mean $\pm \mathrm{SE}$, and results were statistically significant at $P \leq 0.05$

\section{RESULTS}

3.1. Effect effects of thymol and carvacrol administration on serum BUN, creatinine and renal MDA level, CAT, GPX and SOD activities

The obtained result revealed that rats orally administrated with each of thymol and carvacrol for 12 successive days compared to rats that were previously treated with gentamycin $(\mathrm{i} / \mathrm{p})$ showed a significant $(p<0.05)$ decrease in blood urea nitrogen, serum creatinine and renal MDA compared with the rats that were treated with gentamycin only. While there was a significantly increase in the kidney SOD and GPX levels (Table 1-3). 
Table 1 Effects of thymol (20 mg/kg/day orally) and carvacrol $(15 \mathrm{mg} / \mathrm{kg} /$ day orally) administration for 12 successive days on BUN and creatinine levels in rats treated with gentamicin $(100 \mathrm{mg} / \mathrm{kg} /$ day i.p).

\begin{tabular}{lcc}
\hline Groups & Urea $(\mathrm{mg} / \mathrm{dl})$ & Creatinine $(\mathrm{mg} / \mathrm{dl})$ \\
\hline Control & $25.70 \pm 0.82^{\mathrm{c}}$ & $0.74 \pm 0.03^{\mathrm{d}}$ \\
Tween & $25.13 \pm 1.03^{\mathrm{c}}$ & $0.73 \pm 0.01^{\mathrm{d}}$ \\
Gentamicin & $50.37 \pm 3.79^{\mathrm{a}}$ & $1.67 \pm 0.07^{\mathrm{a}}$ \\
Thymol + Gentamicin & $30.53 \pm 4.62^{\mathrm{c}}$ & $0.94 \pm 0.03^{\mathrm{c}}$ \\
Carvacrol + Gentamicin & $39.47 \pm 1.51^{\mathrm{b}}$ & $1.09 \pm 0.06^{\mathrm{b}}$
\end{tabular}

Means $( \pm$ S. E., $\mathrm{n}=6)$ within the same column carrying different superscripts are significan different at $\mathrm{P} \leq 0.05$ based on Tukey's Honestly significant Difference (Tukey's HSD ) test

Table 2 Effect of thymol $(20 \mathrm{mg} / \mathrm{kg} /$ day orally) and carvacrol $(15 \mathrm{mg} / \mathrm{kg} /$ day orally) administration for 12 successive days on MDA concentration and SOD activity in renal tissue homogenate of rats treated with gentamicin (100 $\mathrm{mg} / \mathrm{kg} / \mathrm{day}$ i.p)

\begin{tabular}{lcc}
\hline Groups & MDA (nmol/g tissue) & SOD (U/g tissue) \\
\hline Control & $11.88 \pm 0.37^{\mathrm{c}}$ & $5.170 \pm 0.09^{\mathrm{a}}$ \\
Tween & $11.78 \pm 0.46^{\mathrm{c}}$ & $5.147 \pm 0.07^{\mathrm{a}}$ \\
Gentamicin & $43.25 \pm 3.39^{\mathrm{a}}$ & $1.737 \pm 0.04^{\mathrm{d}}$ \\
Thymol + Gentamicin & $33.34 \pm 2.64^{\mathrm{b}}$ & $3.397 \pm 0.59^{\mathrm{b}}$ \\
Carvacrol + Gentamicin & $28.65 \pm 1.02^{\mathrm{b}}$ & $2.237 \pm 0.22^{\mathrm{c}}$
\end{tabular}

Means ( \pm S. E., $n=6)$ within the same column carrying different superscripts are significant different at $\mathbf{P} \leq 0.05$ based on Tukey's Honestly significant Difference (Tukey's HSD ) test

Table 3 Effect of thymol $(20 \mathrm{mg} / \mathrm{kg} /$ day orally) and carvacrol $(15 \mathrm{mg} / \mathrm{kg} / \mathrm{day}$ orally) administration for 12 successive days on CAT and GPX activities in renal tissue homogenate of rats treated with gentamicin $(100 \mathrm{mg} / \mathrm{kg} / \mathrm{day}$ i.p)

\begin{tabular}{lcc}
\hline Groups & CAT (U/g tissue) & GPX (U/g tissue) \\
\hline Control & $1.23 \pm 0.07^{\mathrm{a}}$ & $82.49 \pm 1.21^{\mathrm{a}}$ \\
Tween & $1.30 \pm 0.07^{\mathrm{a}}$ & $84.67 \pm 0.85^{\mathrm{a}}$ \\
Gentamicin & $0.70 \pm 0.02^{\mathrm{c}}$ & $45.27 \pm 1.84^{\mathrm{d}}$ \\
Thymol + Gentamicin & $0.98 \pm 0.06^{\mathrm{b}}$ & $71.10 \pm 1.35^{\mathrm{b}}$ \\
Carvacrol + Gentamicin & $0.91 \pm 0.04^{\mathrm{b}}$ & $59.02 \pm 1.89^{\mathrm{c}}$ \\
\hline
\end{tabular}

Means $( \pm$ S. E., $n=6)$ within the same column carrying different superscripts are significant different at $\mathrm{P} \leq 0.05$ based on Tukey's Honestly significant Difference (Tukey's HSD ) test

\subsection{Effect on liver enzymes}

In the present study, the activities of serum ALT and ALP were significantly decrease $(p<0.05)$ following administration of thymol and carvacrol(Table 4).

\subsection{Effect on inflammatory markers}

Our study showed that the oral administration thymol or carvacrol with I/P injection of gentamicin reduced $(p<0.05)$ the inflammatory markers (CRP, IL6 and TNF- $\alpha$ ) when compared with rats injected only with gentamicin (Table5).

\subsection{Histopathological examination}

3.4.1. Liver and kidney of rats injected intra-peritoneally with gentamicin (Figure 1).

Liver showed a moderate congestion of hepatic blood vessels with degenerative changes including hydropic degeneration and portal aggregation of round cells. Additionally, multifocal interstitial aggregation of round cells was observed. The bile ducts were mildly hyperplastic, sometime cystic and the kuffer cells were moderately hypertrophied. Mild periportal fibrosis was also seen. Apoptosis of some hepatocytes could be observed in some cases. Kidney showed moderate congestion of renal blood vessels, perivascular edema and focal interstitial round cell aggregations. Large number of renal tubules in both cortex and medulla were cystically dilated and others showed degenerative or necrotic changes, particularly in the renal cortex and around the renal pelvis. The renal pelvis showed congested blood vessels, focal hemorrhage, mucosal necrosis and infiltration of round cells. Moreover, the surrounding renal tubules showed degenerative, necrotic changes and focal coagulate necrosis. Also, some glomeruli were shrinked or lobulated.

Table 4 The effects of thymol $(20 \mathrm{mg} / \mathrm{kg} / \mathrm{day}$ orally) and carvacrol $(15 \mathrm{mg} / \mathrm{kg} /$ day orally) administration for 12 successive days on serum ALT, and ALP activities in rats treated with gentamicin (100mg/kg/day i.p)

\begin{tabular}{lll}
\hline Group & ALT $(\mathrm{U} / \mathrm{L})$ & ALP $(\mathrm{U} / \mathrm{L})$ \\
\hline Control & $12.33 \pm 0.89^{\mathrm{d}}$ & $143.33 \pm 0.88^{\mathrm{d}}$ \\
Tween & $13.33 \pm 0.88^{\mathrm{d}}$ & $142.00 \pm 0.88^{\mathrm{d}}$ \\
Gentamicin & $45.33 \pm 3.53^{\mathrm{a}}$ & $178.33 \pm 3.53^{\mathrm{a}}$ \\
Thymol + Gentamicin & $22.67 \pm 2.60^{\mathrm{c}}$ & $158.00 \pm 2.60^{\mathrm{c}}$ \\
Carvacrol + Gentamicin & $30.33 \pm 2.73^{\mathrm{b}}$ & $166.33 \pm 2.73^{\mathrm{b}}$ \\
\hline Means $( \pm$ S. E., $\mathrm{n}=6)$ within the same column carrying different superscripts are significant
\end{tabular}
different at $\mathrm{P}<0.05$ based on Tukey's Honestly significant Difference (Tukey's HSD ) tes

Table 5 The effects of thymol $(20 \mathrm{mg} / \mathrm{kg} / \mathrm{day}$ orally) and carvacrol $(15 \mathrm{mg} / \mathrm{kg} /$ day orally) administration for 12 successive days on CRP,IL6and TNF- $\alpha$ concentration in rats treated with gentamicin $(100 \mathrm{mg} / \mathrm{kg} /$ day i.p)

\begin{tabular}{llll}
\hline Groups & CRP $(\mathrm{ng} / \mathrm{ml})$ & IL6 $(\mathrm{pg} / \mathrm{ml})$ & TNF- $\alpha(\mathrm{pg} / \mathrm{ml})$ \\
\hline Control & $1.40 \pm 0.23^{\mathrm{d}}$ & $21.3 \pm 0.23^{\mathrm{d}}$ & $14.90 \pm 0.32^{\mathrm{d}}$ \\
Tween & $1.43 \pm 0.24^{\mathrm{d}}$ & $21.27 \pm 0.74^{\mathrm{d}}$ & $14.90 \pm 0.62^{\mathrm{d}}$ \\
Gentamicin & $6.73 \pm 0.23^{\mathrm{a}}$ & $50.60 \pm 1.22^{\mathrm{a}}$ & $30.77 \pm 0.69^{\mathrm{a}}$ \\
Thymol + Gentamicin & $2.50 \pm 0.32^{\mathrm{c}}$ & $28.60 \pm 0.95^{\mathrm{c}}$ & $18.90 \pm 0.36^{\mathrm{c}}$ \\
Carvacrol + Gentamicin & $3.67 \pm 0.26^{\mathrm{b}}$ & $38.43 \pm 1.05^{\mathrm{b}}$ & $24.17 \pm 0.96^{\mathrm{b}}$ \\
\hline
\end{tabular}

Means $( \pm$ S. E., $n=6)$ within the same column carrying different superscripts are significan different at $\mathrm{P}<0.05$ based on Tukey's Honestly significant Difference (Tukey's HSD ) test

3.4.1. Liver and kidney of rats administered orally with thymol and gentamicin (Figure 2):

Most of the hepatic parenchyma appeared normal. While, a few cases showed mild congestion, degenerative changes beside mild portal round cells infiltration and biliary proliferation.

In case of kidney, there was mild to moderate congestion of renal blood vessels with perivascular edema and round cells infiltration. Moderate number of renal tubules showed cystic dilatation and others showed degenerative and necrotic changes. Furthermore, some tubules showed hyaline casts. Some glomeruli were normal while the others were lobulated. The renal pelvis and renal papillae were apparently normal.

\section{DISCUSSION}

Gentamicin is one of the common causes of drug-induced acute kidney injuryin hospitalized patients (Singh et al., 2012). The present study clearly showed the beneficial effect of administration of thymol or carvacrol to countercurrent the negative effects produced by gentamicin in rats.

The present results showed a marked decrease in nephronhepatic and inflammation markers in groups treated with thymol and carvacrol in comparison to administration of gentamycin alone. Similar results were obtained by Hosseinimehr et al. (2015), who investigated the protective effect of thymol as a natural compound against cisplatininduced nephrotoxicity in mice.

Potočnjak and Domitrović(2016)suggested that carvacrol could attenuate the induced acute renal injury by suppressing the oxidative stress, apoptosis, and inflammation. According to our and previous results, both drugs are considered as natural products that have several biological properties such as, free radical scavenging, antioxidant and antiinflammatory activities which are the main mechanisms for 
protection against nephron- and hepatotoxicity (Shimada et al., 2005; Mohan et al., 2006).
The activities of serum ALT and ALP were significantly increased following administration of gentamicin which may be due to oxidative stresses that lead to tissue damage.

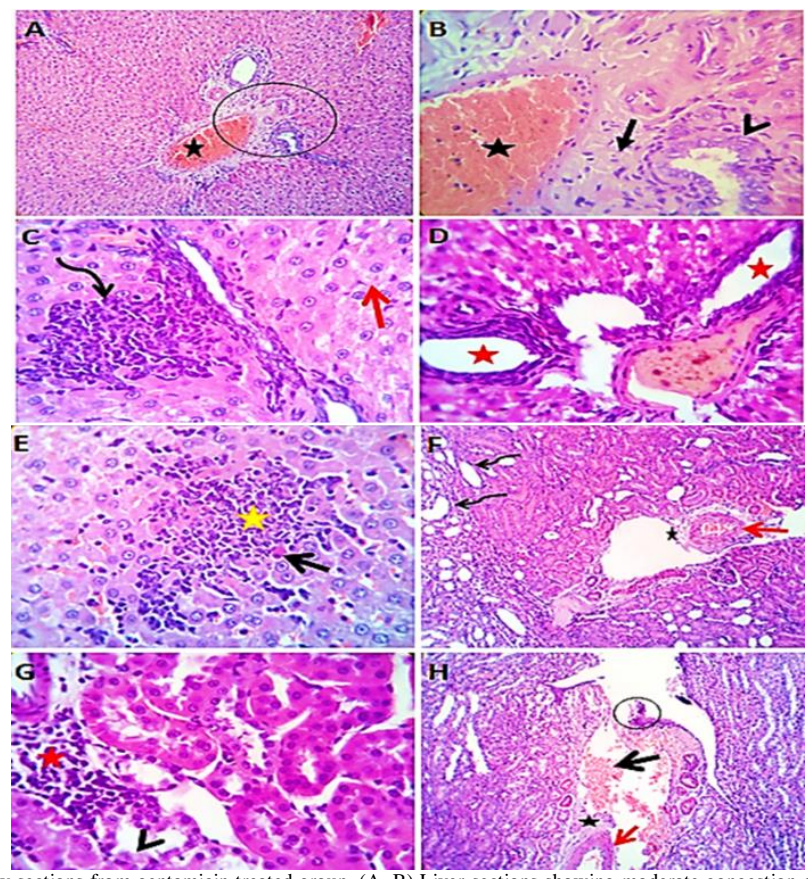

Figure 1 Photomicrograph of liver and kidney sections from gentamicin treated group. (A, B) Liver sections showing moderate congestion of hepatic blood vessels (stars),mild periportal fibrosis (closed arrow) with hyperplastic changes of bile duct (arrow head).(C,D, E) Photomicrograph of liver showing degenerative changes mainly hydropic degeneration (red arrow) and portal aggregation of round cells (curved arrow), cystic changesof bile ducts epithelium (red stars)and multifocal interstitial aggregation of round cells (yellow star). Beside apoptotic change portal aggregation of round cells (curved arrow), cystic changesof bile ducts epithelium (red stars)and multifocal interstitial aggregation of round cells (yellow star). Beside apoptoticchange (open arrow) of some hepatocytes.(F,G,H) Kidney sections showing moderate congestion of renal blood vessels (red arrow), perivascular edema (stars), Large number of renal tubules in
both cortex , medulla showing cystic dilatation (curved arrows,focal interstitial round cell aggregations (red star). and others with degenerative changes (arrowhead)and focal hemorrhage (arrow) with mucosal necrosis (circle) of renal pelvis epithelium. H\&E X 100 (A,F,H), 400(B,C,D,G)
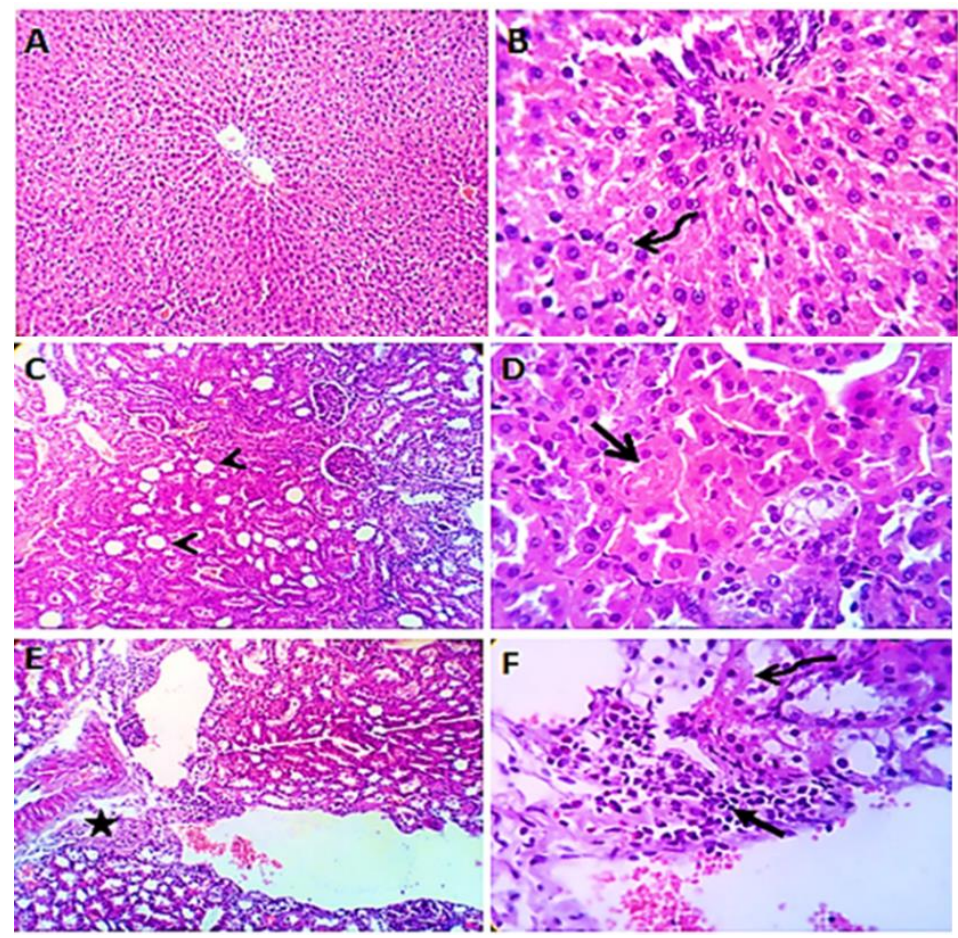

Figure 2 Photomicrograph of liver and kidney sections from Thymol+Gentamicin. (A,B) liver sections showing normal hepatic parenchyma with degenerative changes( (curved arrow) in some hepatocytes.(C,D,E,F) Kidney sections showing moderate number of renal tubules showing cystic dilatation (arrow heads), hyaline casts (open arrow) within tubular lumen, perivascula edema (star),perivascular round cells infiltration (closed arrow), and other tubular epithelium showing necrotic changes (curved arrow). H\&EX 100(A,C,E) ,400(B, D,F)

According to our and previous studies, thymol and carvacrol with gentamicin showed a significant decline in activities of group. Thymol and carvacrol could enhance the antioxidant serum ALT and ALP when compared with gentamicin defense mechanism and increased self-antioxidant enzyme activities (Gholijani et al., 2015). Also, they inhibited 
oxidative stress damage such as lipid peroxidation (Özkan and Erdoğan, 2011).

Moreover, our histological examinations showed the appearance of normal renal and hepatic parenchyma treated with thymol or carvacrol with gentamycin once daily for 12 successive days. Similarly, carvacrol could protect the histological structure in nephrotoxic rats induced by gentamycin (Gunes et al., 2016) Additionally, both herbal drugs caused a significant suppression in inflammation markers(CRP, TNF- aand IL-6). However, the higher reduction of such markers was produced in thymolgroup in comparison to carvacrol group. The present data showed that thymol has more antioxidant and anti-inflammatory effects than carvacrol. Similar results were reported by (Alam et al., 1999; Liang et al., 2014). To explain such superior effects of thymol, further investigations are required.

\section{CONCULOSION}

The present study clearly reported the degenerative changes in testes induced by gentamycin and importantly, the beneficial effects of the coadministration of thymol and carvacrol on the kidney and liver functions by reduction of the oxidative stress. These results can suggest the consideration of thymol and carvacrolas protective and antioxidant agents during gentamycin administration.

\section{REFERENCES}

1. Abdel-Raheem, I. T., Abdel-Ghany, A. A., and Mohamed, G. A. 2009.Protective effect of quercetin against gentamicininduced nephrotoxicity in rats. Biological and Pharmaceutical Bulletin, 32(1), 61-67.

2. Adaramoye, O. A., Osaimoje, D. O., Akinsanya, A. M., Nneji, C. M., Fafunso, M. A.,and Ademowo, O. G. 2008.Changes in antioxidant status and biochemical indices after acute administration of artemether, artemether-lumefantrine and halofantrine in rats. Basic and clinical pharmacology and toxicology, 102(4), 412-418.

3. Ahmadvand, H., Tavafi, M., Asadollahi, V., Jafaripour, L., Hadipour-Moradi, F., Mohammadrezaei-Khoramabadi, R., Khosravi, P., Salehi, H. and Cheraghi, A., 2016.Protective effect of carvacrol on renal functional and histopathological changes in gentamicin-induced-nephrotoxicity in rats. Zahedan Journal of Research in Medical Sciences, 18(4):2933

4. Alam, K., Nagi, M.N., Badary, O.A., Al-Shabanah, O.A., AlRikabi, A.C. and Al-Bekairi, A.M., 1999.The protective action of thymol against carbon tetrachloride hepatotoxicity in mice. Pharmacological research, 40(2): 159-163.

5. Aligiannis, N., Kalpoutzakis, E., Mitaku, S., and Chinou, I. B. 2001.Composition and antimicrobial activity of the essential oils of two Origanum species. Journal of agricultural and food chemistry, 49(9), 4168-4170.

6. Alinezhad, H., Azimi, R., Zare, M., Ebrahimzadeh, M. A. Eslami, S., Nabavi, S. F. and Nabavi, S. M.2013. Antioxidant and antihemolytic activities of ethanolic extract of flowers, leaves, and stems of Hyssopusofficinalis L. Var. angustifolius. International journal of food properties, 16(5), $1169-1178$

7. Aristatile, B., Al-Numair, K. S., Veeramani, C., and Pugalendi, K. V. 2009.Effect of carvacrol on hepatic marker enzymes and antioxidant status in d-galactosamine-induced hepatotoxicity in rats. Fundamental and clinical pharmacology, 23(6), 757-765.
8. Aristatile, B., Al-Numair, K. S., Al-Assaf, A. H., Veeramani, C., and Pugalendi, K. V. 2015.Protective effect of carvacrol on oxidative stress and cellular DNA damage induced by UVB irradiation in human peripheral lymphocytes. Journal of biochemical and molecular toxicology, 29(11), 497-507.

9. Astin, J. A. 1998. Why patients use alternative medicine: results of a national study. Jama, 279(19), 1548-1553.

10. Balakumar, P., WitnessKoe, W. E., Gan, Y. S., JemayPuah, S M., Kuganesswari, S., Prajapati, S. K., Varatharajan R., Jayachristy S.A., Sundram K., Bahari, M. B. 2017.Effects of pre and post-treatments with dipyridamole in gentamicininduced acute nephrotoxicity in the rat. Regulatory Toxicology and Pharmacology, 84, 35-44.

11. Bancroft, J. D., and Gamble, M. (Eds.).2008. Theory and practice of histological techniques. Elsevier health sciences.

12. Basnakian, A.G.,Kaushal, G. P., and Shah, S. V. 2002.Apoptotic pathways of oxidative damage to renal tubular epithelial cells. Antioxidants and Redox Signaling, 4(6), 915924.

13. BLAzKA, M. E., Wilmer, J. L., HoLLADAY, S. D., WILsoN, R. E., and Luster, M. I. 1995.Role of proinflamma-tory cytokines in acetaminophen hepatotoxicity. Toxicol Appl Pharmacol, 133(1), 43-52.

14. Dhanarajan, R., Abraham, P., and Isaac, B. 2006.Protective Effect of Ebselen, a Selenoorganic Drug, against GentamicinInduced Renal Damage in Rats. Basic and clinical pharmacology and toxicology, 99(3), 267-272.

15. Gardner, C. R., Laskin, J. D., Dambach, D. M., Chiu, H., Durham, S. K., Zhou, P., and Laskin, D. L. 2003.Exaggerated hepatotoxicity of acetaminophen in mice lacking tumor necrosis factor receptor-1: Potential role of inflammatory mediators. Toxicol Appl Pharmacol, 192(2), 119-130.

16. Gholijani, N., Gharagozloo, M., Kalantar, F., Ramezani, A. and Amirghofran, Z. 2015. Modulation of cytokine production and transcription factors activities in human Jurkat $\mathrm{T}$ cells by thymol and carvacrol. Advanced pharmaceutical bulletin, 5(Suppl 1), 653 .

17. Gunes, S., Ayhanci, A., Sahinturk, V., Altay, D.U. and Uyar, R., 2017.Carvacrol attenuates cyclophosphamide-induced oxidative stress in rat kidney. Canadian journal of physiology and pharmacology, 95(7), pp.844-849.

18. Halliwell, B. 1995. Antioxidant characterization: methodology and mechanism. Biochemical pharmacology 49(10), 1341-1348

19. Hosseinimehr, S. J., Asadian, R., Naghshvar, F., Azizi, S., Jafarinejad, M., Noaparast, Z., and Hosseini, S. A. H 2015.Protective effects of thymol against nephrotoxicity induced by cisplatin with using $99 \mathrm{mTc}$-DMSA in mice. Renal failure, 37(2), 280-284

20. Kohen, R., andNyska, A. 2002. Invited review: Oxidation of biological systems: oxidative stress phenomena, antioxidants, redox reactions, and methods for their quantification Toxicologic Pathology, 30(6), 620-650.

21. Li, H., Yang, T., Li, F. Y., Yao, Y., and Sun, Z. M. 2014.Antibacterial activity and mechanism of action of Monardapunctata essential oil and its main components against common bacterial pathogens in respiratory tract. International journal of clinical and experimental pathology, 7(11), 7389-7398.

22. Liang, D., Li, F., Fu, Y., Cao, Y., Song, X., Wang, T., Wang, W., Guo, M., Zhou, E., Li, D. and Yang, Z., 2014.Thymol inhibits LPS-stimulated inflammatory response via downregulation of NF- $\mathrm{KB}$ and MAPK signaling pathways in mouse mammary epithelial cells. Inflammation, 37(1): 214-222.

23. Lopez-Novoa, J. M., Quiros, Y., Vicente, L., Morales, A. I., and Lopez-Hernandez, F. J. 2011. New insights into the mechanism of aminoglycoside nephrotoxicity: an integrative point of view. Kidney International, 79(1): 33-45.

24. Malyszko, J., Lukaszyk, E., Glowinska, I., and Durlik, M. 2015. Biomarkers of delayed graft function as a form of acute kidney injury in kidney transplantation. Scientific Reports, 5:1-9. 
25. Mohan, I.K., Khan, M., Shobha, J.C., Naidu, M.U.R., Prayag, A., Kuppusamy, P. and Kutala, V.K., 2006.Protection against cisplatin-induced nephrotoxicity by Spirulina in rats.Cancer Chemotherapy and Pharmacology, 58(6): 802-808.

26. Nabavi, S. M., Marchese, A., Izadi, M., Curti, V., Daglia, M. andNabavi, S. F. 2015. Plants belonging to the genus Thymus as antibacterial agents: From farm to pharmacy. Food chemistry, 173, 339-347.

27. Noorani, A. A., Gupta, K., Bhadada, K., and Kale, M. K. 2011. Protective effect of methanolic leaf extract of Caesalpinia Bonduc (L.) on gentamicin-induced hepatotoxicity and nephrotoxicity in rats. Iranian Journal of Pharmacology and Therapeutics, 10(1), 21-25.

28. Özkan, A., and Erdoğan, A. 2011.A comparative evaluation of antioxidant and anticancer activity of essential oil from Origanumonites (Lamiaceae) and its two major phenolic components. Turkish Journal of Biology, 35(6), 735-742.

29. Pedraza-Chaverrí, J., Maldonado, P. D., Medina-Campos, O. N., Olivares-Corichi, I. M., de los Ángeles GranadosSilvestre, M., Hernández-Pando, R., and Ibarra-Rubio, M. E. 2000. Garlic ameliorates gentamicin nephrotoxicity: relation to antioxidant enzymes. Free Radical Biology and Medicine, 29(7), 602-611.

30. Potočnjak, I., andDomitrović, R. 2016.Carvacrol attenuates acute kidney injury induced by cisplatin through suppression of ERK and PI3K/Akt activation. Food and Chemical Toxicology, 98, 251-261.
31. Poulose, A. J., andCroteau, R. 1978. Biosynthesis of aromatic monoterpenes: conversion of $\gamma$-terpinene to p-cymene and thymol in Thymus vulgaris L. Archives of Biochemistry and Biophysics, 187(2), 307-314.

32. Randjelovic, P., Veljkovic, S., Stojiljkovic, N., Sokolovic, D., and Ilic, I. 2017. Gentamicin nephrotoxicity in animals: current knowledge and future perspectives. EXCLI Journal, 16, 388.

33. Shimeda, Y., Hirotani, Y., Akimoto, Y., Shindou, K., Ijiri, Y., Nishihori, T. and Tanaka, K., 2005.Protective effects of capsaicin against cisplatin-induced nephrotoxicity in rats. Biological and Pharmaceutical Bulletin, 28(9): 1635-1638.

34. Singh, A. P., Muthuraman, A., Jaggi, A. S., Singh, N., Grover, K., and Dhawan, R. 2012.Animal models of acute renal failure. Pharmacological Reports, 64(1), 31-44.

35. Soliman, K. M., Abdul-Hamid, M.andOthman, A. I. 2007.Effect of carnosine on gentamicin-induced nephrotoxicity. Medical science monitor, 13(3): BR73-BR83.

36. Tuttolomondo, T., Dugo, G., Ruberto, G., Leto, C., Napoli, E. M., Cicero, N., Gervasi T., Virga G., Leone R., Mario Licata M.and La Bella, S. 2015. Study of quantitative and qualitative variations in essential oils of Sicilian Rosmarinus OfficinalisL. Natural product research, 29(20), 1928-1934.

37. Walker, P. D., Barri, Y., and Shah, S. V. 1999. Oxidant mechanisms in gentamicin nephrotoxicity. Renal Failure, 21(3-4), 433-442. 